\title{
The study of the hardening process Portland cement's concrete with bio cementing additives
}

\author{
Elena S. Dergunova*, Valeria A. Goncharova, Alexey Y. Romanchukevich, and Margarita \\ A. Goncharova
}

Department of Building Materials Science and Road Technologies, Lipetsk State Technical University, 30 Moskovskaya St. 398055 Lipetsk, Russian Federation

\begin{abstract}
The paper presents the results of studying the hardening processes of concrete based on Portland cement using biocementing additives. Isolated 11 strains of various bacteria were used as dietary supplements. The bacteria were grown at a temperature of $30{ }^{\circ} \mathrm{C}$ in an aerated fermenter with a stirrer speed of 550-600 rpm. The morphology of the concrete surface was evaluated before and after the application of the substrate with the nutrient medium; the appearance of a new phase was recorded after 2 weeks. The effect of cementation conditions on the compressive strength of biocemented concrete specimens was studied, and the capillary water`s coefficients absorption were determined.
\end{abstract}

\section{Introduction}

All over the world, most buildings and structures are erected using reinforced concrete structures, which have many advantages. Concrete is the strongest and most effective building material on the market today, it is durable, resists corrosion from steel reinforcement, and is resistant to external influences. However, under prolonged exposure to external influences, its integrity is violated, defects are formed, which lead to a decrease in the initial characteristics. This is a significant disadvantage, since when restoring the working capacity of concrete, it is necessary to carry out a number of examinations and further repair and restoration work [1-2].

Portland cement is one of the most common materials used in construction. Its activity is determined by the mineralogical composition, dispersion, the presence of defects in the structure of minerals, etc. To increase the activity of cement, mechanical action, the introduction of electrolytes, additives of mineral and surfactants, electric and magnetic fields are used [3-6].

Dispersed mineral additives are introduced in order to improve the properties of cement materials, replace part of the cement, and utilize technogenic raw materials. Despite the variety of additives added to cement, their choice is not always justified. The effect of the ratio of the dispersion of additives and cement and the associated optimal amount of additives has not been sufficiently studied [6-10].

\footnotetext{
*Corresponding author: dergunova14@yandex.ru
} 
Currently, all over the world, work is underway to create mortars and concretes with a self-healing microstructure using nature-like technologies. Microbial carbonate biomineralization, an intensively developing area of nature-like technologies, expands the range of tools for managing the processes of structure formation at various technological stages of the life cycle of composite building materials, from designing a raw mixture to self-healing during operation [3, 5, 10-14].

Like any interdisciplinary direction, the technology of carbonate biomineralization in building materials science, having passed the stages of studying natural analogs of the processes expected to be borrowed, theoretically substantiating the prospects for their applied use, has passed into the stage of accumulating empirical results that require generalization and analysis. Taking into account the above, the problem of developing technology and managing the process of obtaining composite building concrete materials using carbonate biomineralization is an urgent task $[3,7,9]$. The purpose of this work is to study the hardening processes of concrete based on Portland cement using biocementing additives.

\section{Methods and materials}

Cement of the PC-400 D0 grade was used as a binder in the standard mixture. Polyfraction sand was used as a fine aggregate for conventional mortar mixtures. Technical water was used in the mortar mixture.

Isolated strains of bacteria Sp. pasteurii (B1), B. pasteurii (B2), B. Cohnii (B3), B. Sphaericus (B4), B. Pseudofirmus (B5), B. Cohnii (B6), B. Halodurans (B7), B. subtilis (B8), B. Megaterium (B9), B. alkalinitrilicus (B10), Ps. putida (B11). The bacteria were grown at a temperature of $30{ }^{\circ} \mathrm{C}$ in an aerated fermenter with a stirrer speed of 550-600 $\mathrm{rpm}$. After 48 hours, the bacterial culture reached an optical density (OD $546 \mathrm{Nm}$ ) of about 4.8 - 5.2. To determine the urease activity, Christensen's medium with urea was used. CFU was determined using test sliders [4].

To study the regularities of the growth of a new phase, we used the data obtained by atomic force microscopy, AFM (scanning probe microscope Solver P47-PRO ZAO Nanotechnology-MDT, Russia), optical microscopy - a DigiMicroSkale microscope (DNT, Germany).

\section{Discussion}

Modeling the process of bacterial growth. The general principle of the self-healing process of concrete is that when various types of external loads (static, dynamic, in combination with the possible presence of an aggressive chemical environment) are applied to building structures, microcracks appear in the surface and near-surface layers of the material, into which air and moisture from the natural environment. Under these conditions, bacteria, previously introduced into the composition of the material together with the nutrient medium, are activated, and as a result of the ongoing biochemical processes, calcium carbonate is formed, which performs the functions of biomineralization, providing the processes of self-healing of the structure and operational characteristics of the material [1, $2,5]$. After filling the defective volume of the crack with calcium carbonate, the air and moisture necessary to ensure the activity of the cells cease to flow and the microorganisms pass into a state of suspended animation. Bacteria thrive on the nutrient calcium lactate to form limestone that fills in cracks and hardens.

Urease activity is found in a wide range of microorganisms and plants, some of which produce the enzyme in large quantities. For example, ordinary alkalophilic (alkali-loving) 
soil bacteria have a high urease activity. This bacterium uses urea as an energy source and produces ammonium ions $\left(\mathrm{NH}_{4}^{+}\right)$, which increase the $\mathrm{pH}$ of the environment and cause precipitation of $\mathrm{Ca}^{2+}$ and $\mathrm{CO}_{3}{ }^{2-}$ ions in the form of calcium carbonate $\mathrm{CaCO}_{3}$. A local increase in $\mathrm{pH}$ is often caused by the fact that bacterial cells have become the nucleation centers for crystallization. Calcite deposition is described by the following average reaction equation: $\mathrm{Ca}^{2+}+\mathrm{CO}_{3}{ }^{2-}=\mathrm{CaCO}_{3}[3]$.

Microbiologically induced calcite deposition proceeds according to the equations [3]:

$$
\begin{aligned}
& \mathrm{Ca}^{2+}+\mathrm{HCO}_{3}^{-}+\mathrm{OH}^{-}=\mathrm{CaCO}_{3}+\mathrm{H}_{2} \mathrm{O} \\
& \mathrm{Ca}^{2+}+2 \mathrm{HCO}_{3}{ }^{-}=\mathrm{CaCO}_{3}+\mathrm{CO}_{2}+\mathrm{H}_{2} \mathrm{O} .
\end{aligned}
$$

As mentioned above, the precipitation of calcium carbonate from the solution will be favored by any microbiological processes leading to an increase in the content of bicarbonate ions in the medium.

To study the growth of a colony of microorganisms on a concrete plane [6-9], it is necessary to study the morphological and temporal characteristics of such growth under various initial conditions, as well as to establish the relationship between the morphological characteristics of bacteria and their growth rate as a factor that generally characterizes their activity. In this model, each microorganism in the colony is modeled separately, and this approach allows us to better understand the statistical principles of the growth kinetics of microorganisms. The advantage of this model is that generalized growth characteristics of the entire colony are obtained by modeling the behavior of a large number of individual microorganisms with their inherent parameters.

When developing the model, the following assumptions were made: the area of distribution of microorganisms is a limited part of the plane with a discrete grid, this representation facilitates the calculation of morphological parameters; the unit of time in the model is iteration; the nutrient at the initial time is evenly distributed over the distribution points; the microorganism consumes all the nutrient that is located at its distribution point; the diffusion of the nutrient in the system is determined by mass transfer from neighboring cells, which occurs with each iteration. The colony shape changes only due to cell reproduction; the maximum cell lifetime is determined by the probability distribution; at the initial moment, microorganisms are sown in $\mathrm{n}$ cells of the distribution area, their position can be either random (spontaneous inoculation) or fixed by the coordinates of the cells in which they are found (artificial inoculation). The age of microorganisms present in the system at the initial time is recorded by the corresponding distribution. The kinetics obtained in the model varies significantly depending on the location of inoculated cells, which means that biological kinetics is not reproducible using deterministic models. At the initial stage of development, while individual colonies do not interact with each other, the dynamics are almost the same, but in the subsequent interaction of individual colonies, the growth dynamics changes significantly and depends more on the nature of this interaction than on the initial conditions for the development of the bacterial population.

An acute issue for biocementation is the time of the appearance of a new phase. The period of time during which the nuclei of calcium carbonate appears (Fig. 1) was investigated. The dependence of the population size on the fractal dimension of its image at the initial stage of population development is obtained.

A study of the structural characteristics of concrete samples based on Portland cement showed that the resulting calcium carbonate, settling, fills the pore space of the samples [9$10]$.

Determination of water absorption of samples. Samples of concrete on the base must have sufficient compressive strength in dry conditions; however, the material will lose strength when the moisture content is unfavorable [15]. Therefore, in this case, the amount of water absorption allowed by concrete samples is of great importance. 

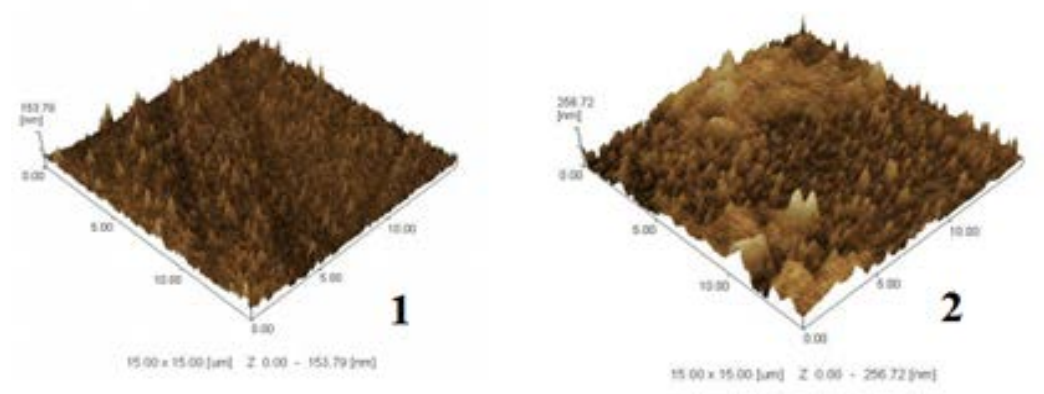

Fig. 1. The morphology of the concrete surface after applying the substrate with the nutrient medium (for example B3: 1 - exposure time 1 week, 2 - exposure time 2 weeks).

The water absorption test method can serve as a basis for analyzing test data for characteristics such as the water absorption coefficient (Aw) (indicating the water absorption properties of the material) and the point at which the material deforms (the amount of water absorbed before breaking), thus showing the effect of moisture migration for adhesion of Portland cement. Modification of the capillary uptake rate data was obtained using the standard procedure [15] with cylindrical test blocks $9 \mathrm{~mm}$ high $\times 13 \mathrm{~mm}$ in diameter placed in contact with the test liquid (deionized water) in a shallow graduated tray (immersion depth $2 \mathrm{~mm}$ ). Water was absorbed through the bottom edge. The weight gain of the sample was measured at intervals until the water level reached a predetermined mark (Table 1).

Table 1. Evaluation of the capillary water absorption coefficient when using certain types of bacterial additives.

\begin{tabular}{|c|c|c|}
\hline № $\Pi / \Pi$ & $\begin{array}{c}\text { The Bacterial additive } \\
(0.5 \% \text { mass. })\end{array}$ & $\begin{array}{c}\text { The water absorption coefficient, } \\
\mathrm{Aw}, \mathrm{kg} /\left(\mathrm{m}^{2} \cdot \mathrm{min}^{0,5}\right)\end{array}$ \\
\hline 1 & - & 0,0170 \\
\hline 2 & 51 & 0,0122 \\
\hline 3 & 53 & 0,0110 \\
\hline 4 & 55 & 0,0157 \\
\hline
\end{tabular}

Compaction of the structure leads to a decrease in the porosity of the concrete sample by 1.25 times and, accordingly, reduces its capillary water absorption coefficient from 0.0170 to $0.0011 \mathrm{~kg} /\left(\mathrm{m}^{2} \cdot \mathrm{min}^{0.5}\right)$ at the age of 4 weeks (28 days) for samples with 0.5 $1 \%$ (by weight) of the microbiological additive $\mathrm{B} 3$.

Influence of cementation conditions on the compressive strength of biocemented cylindrical specimens. The compressive strength was a modification of a validated test equipment using the established specifications for miniature biostabilized blocks and the stress required at the break point is described by this test (compressive stress in $\mathrm{MPa}$ ) (Table 2).

Table 2. Evaluation of the compression resistance of concrete samples based on Portland cement with the use of various biocementing additives.

\begin{tabular}{|l|l|l|l|l|l|l|l|l|l|l|l|}
\hline $\begin{array}{l}\text { Portland } \\
\text { cement PC- } \\
400 \text { D0 }\end{array}$ & B1 & B2 & B3 & B4 & B5 & B6 & B7 & B8 & B9 & B10 & B11 \\
\hline $\begin{array}{l}\text { Compression } \\
\text { resistance, } \\
\text { MPa }\end{array}$ & 51,8 & 45,9 & 60,8 & 52,7 & 18,8 & 41,7 & 38,9 & 40,5 & 22,3 & 22,9 & 12,6 \\
\hline
\end{tabular}


Conventional Portland cement PC-400D0 was used as a reference material for the above tests. Were investigated concrete samples with additives B1 - B11. The best results were shown by samples with the additive B3.

The result of the control test was $60.5 \mathrm{MPa}$, showing that more force is required for the destruction of a concrete block with additive B3.

\section{Conclusion}

Micro-adhesion is believed to be a factor contributing to effective adhesion performance as measured at the macro level. Hypothetical mechanisms include the generation of particlebinding materials through microbial processes in situ so that the shear strength of concrete can be increased; and the production of porous materials using microbial agents to significantly reduce the hydraulic conductivity of concrete matrices. The products of microbial fermentation processes usually consist of a functional consortium of fermented organics, active whole cell bacteria, spores, enzymes, biopolymers, biosurfactants, and other ingredients. New research on these new primary and secondary metabolites from microbes, as well as an understanding of the stability of the microstructural characteristics of concrete, will lead to deeper knowledge for wider applications at the macro level. The original test program was aimed at demonstrating the effectiveness of the dietary supplement in terms of adhesion performance. The next stage of the study will be devoted to the characterization of agents (physiological, biochemical and mechanisms of biogeochemical processes). Structural strength properties, including compressive strength tests, will be part of the next phase of the test program and finally field validation.

\section{References}

1. C. Nething, M. Smirnova, J. A. D. Gröning, W. Haase, A. Stolz, W. Sobek, A method for 3D printing bio-cemented spatial structures using sand and urease active calcium carbonate powder, Materials \& Design, V.195, 109032 (2020)

2. C. Chandrasiri, T. Yehdego, S. Peethamparan, Synthesis and characterization of bio-cement from conch shell waste, Construction and Building Materials, V. 212, pp. 775-786 (2019)

3. M.F. Irfana, S.M.Z. Hossaina, H. Khalida, F. Sadafa, S. Al-Thawadib, A. Alshatera, M.M. Hossainc, S.A. Razzakc, Optimization of bio-cement production from cement kiln dust using microalgae, Biotechnology Reports, V. 23, e00356 (2019)

4. J. M. van der Bergh, B. Miljevic, O. Sovljanski, S. Vucetic, S. Markov, J. Ranogajec, A Bras, Preliminary approach to bio-based surface healing of structural repair cement mortars, Construction and Building Materials, V. 248, 118557 (2020)

5. C. Qian, X. Yu, X. Wang, A study on the cementation interface of bio-cement, Materials Characterization, V. 136, pp. 122-127 (2018)

6. X. Yu, C. Qian, L. Sun, The influence of the number of injections of bio-composite cement on the properties of bio-sandstone cemented by bio-composite cement, Construction and Building Materials, V. 164, pp. 682-687 (2018)

7. Y.J. Phua, A. Royne, Bio-cementation through controlled dissolution and recrystallization of calcium carbonate, Construction and Building Materials, V.167, pp. 657-668 (2018)

8. Q. Zhan, C. Qian, Stabilization of sand particles by bio-cement based on CO2 capture and utilization: Process, mechanical properties and microstructure, Construction and Building Materials, V. 133, pp. 73-80 (2017)

9. M. Lia, C. Fang, S. Kawasaki, M. Huang, V. Achal, Bio-consolidation of cracks in masonry cement mortars by Acinetobacter sp. SC4 isolated from a karst cave, International Biodeterioration \& Biodegradation, V. 141, pp. 94-100 (2019)

10. X. Yu, C. Qian, B. Xue, Loose sand particles cemented by different bio-phosphate and carbonate composite cement, Construction and Building Materials, V.113, pp. 571-578 (2016) 
11. J. Lian, Y. Yan, H. Xu, D. Fu, Quantitative method of calcium carbonate in bio-grouting test under multiple treatment factors, Construction and Building Materials, V.259, 120384 (2020)

12. K. Feng, B.M. Montoya, T.M. Evans, Discrete element method simulations of bio-cemented sands, Computers and Geotechnics, V. 85, pp. 139-150 (2017)

13. X. Yu, C. Qian, B. Xue, X. Wang, The influence of standing time and content of the slurry on biosandstone cemented by biological phosphates, Construction and Building Materials, V. 82, pp. 167-172 (2015)

14. M. Abdulkareem, F. Ayeronfe, M. Zaimi, A. Majid, A. R. Mohd. Sam, J.-H. J. Kim, Evaluation of effects of multi-varied atmospheric curing conditions on compressive strength of bacterial (bacillus subtilis) cement mortar, Construction and Building Materials, V. 218, pp. 1-7 (2019)

15. V. M. Ramdas, P. Mandree, M. Mgangira, S. Mukaratirwa, R. Lalloo, S. Ramchuran, Establishing miniaturised structural testing techniques to enable high-throughput screening of microorganisms and microbial components for unpaved road stabilisation application, Journal of Advanced Research, V.21, pp. 151-159 (2020) 